\title{
Application of asymmetric current for electrocoagulation treatment of oil-containing waste water
}

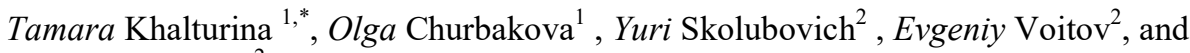 \\ Denis Balchugov ${ }^{2}$ \\ ${ }^{1}$ Siberian Federal University, 660041, 23 (A), Svobodny Ave., Krasnoyarsk, Russia \\ ${ }^{2}$ Novosibirsk State University of Architecture and Civil Engineering, 630008, 113, Leningradskaya, \\ Novosibirsk, Russia
}

\begin{abstract}
The goal of the work was to study the electrocoagulation of oily wastewater using an asymmetric current and to determine the composition of the resulting sludge for disposal. The planning of the experiment according to Box-Hunter method was given and mathematical models regression equations of the electrocoagulation process of oily wastewater using an asymmetric current were obtained. Optimization was performed by the dissociative-step method due to the regression equations. The structure and composition of sludge obtained under optimal electrocoagulation conditions using asymmetric current for the disposal of sludge in the arbolite mixtures production were studied. The results of experimental studies can be used to develop low-waste efficient, energysaving technologies for wastewater treatment and waste management.
\end{abstract}

\section{Introduction}

The introduction of low-waste technological processes at the treatment facilities of industrial enterprises is necessary to reduce the technological impact on the environment. Electrochemical methods are the most applicable for wastewater treatment in the conditions of machine-building and metallurgical production for Siberia and the Far North.

The literature and patent documentation analysis showed that numerous works were devoted to the treatment of oily wastewater [1-2], however, methods for intensifying electrocoagulation of wastewater to develop and implement effective, energy-saving technologies in remote inaccessible industrial areas with infrastructural difficulties had not been covered enough.

The aim of the research was to study the electrocoagulation of oily wastewater using an asymmetric current and to determine the composition of the resulting sludge for disposal.

* Corresponding author: michmacha@mail.ru 


\section{Materials and research methods}

Oil product concentrations were determined using IS spectrophotometric method on CN-2 concentrator. For an experimental study of the composition and structure of the precipitate, an X-ray phase analysis was performed with the use of D8-ADVANCE diffractometer of the German company Bruker-ASX, and a thermogravimetric analysis was performed with the use of NETZSCH STA 449F1 instrument, in the range of $30 / 200 \mathrm{~K} / \mathrm{min} / 1000$.

The research results were obtained in the process of Box-Hunter experiment planning in dynamic conditions on an electrocoagulator with a working volume of $400 \mathrm{ml}$, flat aluminum electrodes with their working surface of $2.96 \mathrm{dm}^{2}$, the distance between plates was $10 \mathrm{~mm}, \mathrm{pH}=6,8-7$, which made it possible to identify factors affecting the process of oily wastewater purification and the degree of their interaction. Electrocoagulation was performed using an asymmetric current.

The asymmetric current was obtained using a device, which had been developed at the "Engineering Systems of Buildings and Structures" Department of School of Engineering and Construction of SibFU [3], and presented in Figure 1 [4].

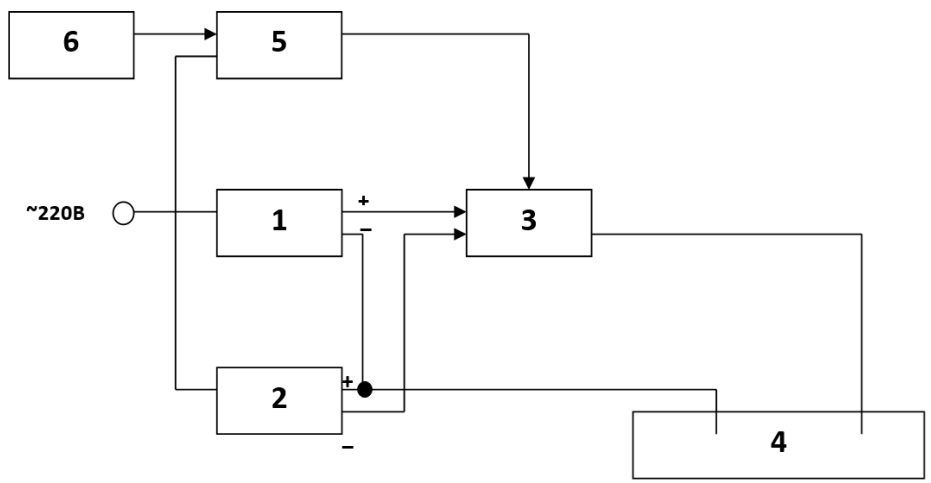

1- adjustable switching power supply (direct current);

2 - adjustable switching power supply (reverse current);

3 - switch; 4 - electrolyzer; 5 - control unit (master oscillator); 6 - computer

Fig. 1. Block diagram of the installation for obtaining asymmetric current.

\section{Research results}

Variable parameters were adopted: $\mathrm{x}_{1}$ was direct current amplitude, $\mathrm{A} ; \mathrm{x}_{2}$ was the amplitude of the reverse current, $\mathrm{A} ; \mathrm{x}_{3}$ was period, $\mathrm{s} ; \mathrm{x}_{4}$ was the duration of the reverse current, $\mathrm{s} ; \mathrm{x}_{5}$ was initial concentration of oil products, $\mathrm{mg} / \mathrm{dm}_{3} ; \mathrm{x}_{6}$ was contact time, min during planning the experiment on electrocoagulation of effluents containing emulsified oil products with the use of asymmetric current.

Evaluation criteria were: $\mathrm{y}_{1}$ was oil content in purified water, $\mathrm{mg} / \mathrm{dm}_{3} ; \mathrm{y}_{2}$ was the specific energy consumption, $\mathrm{kW} \bullet \mathrm{h} / \mathrm{m}_{3}$. The main levels, ranges of variation are given in table 1.

Processing of experimental data made it possible to obtain mathematical models of the oil-containing wastewater electrical treatment with an asymmetric current:

1. relative to the residual concentration of petroleum products:

$\mathrm{Y}_{1}=1.55-0.26 \mathrm{X}_{1}-0.102 \mathrm{X}_{3}+0.144 \mathrm{X}_{4}+0.12 \mathrm{X}_{5}+0.203 \mathrm{X}_{1} \mathrm{X}_{2}+0.267 \mathrm{X}_{1} \mathrm{X}_{4}-0.197 \mathrm{X}_{2} \mathrm{X}_{5}-$ $0.1 \mathrm{X}_{2} \mathrm{X}_{6}+0.11 \mathrm{X}_{3} \mathrm{X}_{4}+0.25 \mathrm{X}_{4} \mathrm{X}_{5}-0 ., 37 \mathrm{X}_{3} \mathrm{X}_{5}-0.12 \mathrm{X}_{3} \mathrm{X}_{6}-0.21 \mathrm{X}_{4} \mathrm{X}_{6}+0.133 \mathrm{X}_{1}^{2}+0.26 \mathrm{X}_{2}^{2}$ $+0.19 \mathrm{X}_{6}^{2}$

2. relative to specific electricity consumption: 
$\mathrm{Y}_{2}=23.4+5.5 \mathrm{X}_{1}+12.96 \mathrm{X}_{2}-3.55 \mathrm{X}_{3}+10.8 \mathrm{X}_{4}-3.3 \mathrm{X}_{5}+6.6 \mathrm{X}_{6}+1.81 \mathrm{X}_{1} \mathrm{X}_{2}+3.87 \mathrm{X}_{1} \mathrm{X}_{4}-$ $1.83 \mathrm{X}_{1} \mathrm{X}_{5}-3.32 \mathrm{X}_{2} \mathrm{X}_{3}+10.98 \mathrm{X}_{2} \mathrm{X}_{4}-0.24 \mathrm{X}_{2} \mathrm{X}_{5}-1.81 \mathrm{X}_{2} \mathrm{X}_{6}-4 \mathrm{X}_{3} \mathrm{X}_{4}-2.47 \mathrm{X}_{3} \mathrm{X}_{6}-3.6 \mathrm{X}_{4} \mathrm{X}_{5}+$ $2.25 \mathrm{X}_{4} \mathrm{X}_{6}+2.75 \mathrm{X}_{2}^{2}$

Table 1. The main levels and intervals of variation.

\begin{tabular}{|c|c|c|c|c|c|c|}
\hline Factor & Interval & +2.378 & +1 & 0 & -1 & -2.378 \\
\hline $\mathrm{X}_{1}$ & 0.5 & 2.69 & 2 & 1.5 & 1 & 0.21 \\
$\mathrm{X}_{2}$ & 1.0 & 4.9 & 3.5 & 2.5 & 1.5 & 0.12 \\
$\mathrm{X}_{3}$ & 20 & 127.6 & 100 & 80 & 60 & 32.44 \\
$\mathrm{X}_{4}$ & 29 & 101.3 & 60 & 30 & 1 & 0 \\
$\mathrm{X}_{5}$ & 300 & 1426 & 1113 & 813 & 513 & 100 \\
$\mathrm{X}_{6}$ & 3 & 17.13 & 13 & 10 & 7 & 2.66 \\
\hline
\end{tabular}

The influence of variable factors on the output parameter value was estimated by reducing the regression equations to a natural scale. Graphic dependencies were obtained, presented in Figures 2 and 3, which are non-linear. Figure 2 shows that the residual concentration of oil products decreases to a certain value, with an increase in the forward current amplitude and its duration, a decrease in the duration of the reverse current and the initial concentration of oil products.

However, a further increase in the varied parameters leads to the cleaning process deterioration. Similar dependences are also observed for the power consumption in Figure 2. The non-linear nature of the curves for the residual concentration of oil products and for the specific power consumption allows choosing the optimal processing conditions.
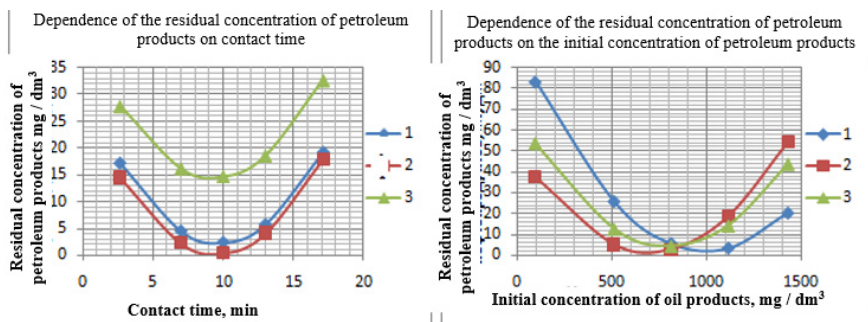

a) $1-$ Irev $=1,5 \mathrm{~A} ; 2-\mathrm{Irev}_{2}=2,5 \mathrm{~A} ; 3-\mathrm{Irev}=3,5 \mathrm{~A}$
$\mathrm{~T}=80 \mathrm{~s} ; \tau_{\mathrm{ree}}=30 \mathrm{~s} ; \mathrm{CPp}_{\mathrm{rii}}=813 \mathrm{mg} / \mathrm{dm}^{3} ; \mathrm{Ifor}=1,5 \mathrm{~A}$
Dependence of the residual concentration of petroleum

b) $1-\mathrm{T}=60 \mathrm{~s} ; 2-\mathrm{T}=80 \mathrm{~s} ; 3-\mathrm{T}=100 \mathrm{~s}$

Irev $=2,5 \mathrm{~A} ;$ trev $=30 \mathrm{~s} ; \mathrm{t}=10 \mathrm{~min} ; \mathrm{Ifor}=1,5 \mathrm{~A}$
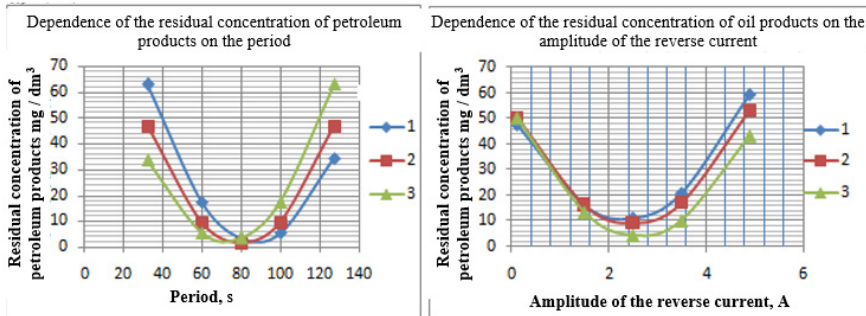

e) $1-$ Ifor $=1,0 \mathrm{~A} ; 2-$ Ifor $=1,5 \mathrm{~A} ; 3-$ Ifor $^{2}=2,0 \mathrm{~A}$ $\mathrm{T}=80 \mathrm{~s} ; \mathrm{Trev}_{\mathrm{rev}}=30 \mathrm{~s} ; \mathrm{CPp}_{\mathrm{ini}}=813 \mathrm{mg} / \mathrm{dm}^{3} ; \mathrm{tr}=10 \mathrm{~min}$

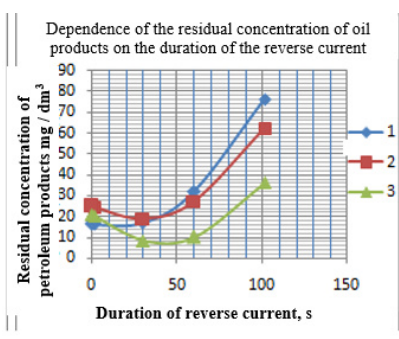

c) $1-\mathrm{Cpp}_{\mathrm{ini}}=513 \mathrm{mg} / \mathrm{dm}^{3} ; 2-\mathrm{Cpp}_{\mathrm{in}}=813 \mathrm{mg} / \mathrm{dm}^{3}$; 3- $\mathrm{Cpp}_{\mathrm{ini}}=1113 \mathrm{mg} / \mathrm{dm}^{3} ; \mathrm{T}=80 \mathrm{~s} ; \mathrm{t}=10 \mathrm{~min} ; \mathrm{Ifor}=1,5 \mathrm{~A}$ Dependence of the residual concentration of oil

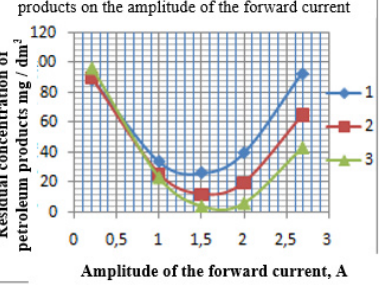

f) $1-\mathrm{t}_{\mathrm{k}}=7 \mathrm{~min} ; 2-\mathrm{t}_{\mathrm{k}}=10 \mathrm{~min} ; 3-\mathrm{t}_{\mathrm{k}}=13 \mathrm{~min}$ $\mathrm{T}=80 \mathrm{~s} ; \tau_{\mathrm{ret}}=30 \mathrm{~s} ; \mathrm{Cpp}_{\mathrm{ini}}=813 \mathrm{mg} / \mathrm{dm}^{3} ; \mathrm{Iret}=2,5 \mathrm{~A}$

d) $1-\tau_{\text {rev }}=1 \mathrm{~s} ; 2-\tau_{\mathrm{res}}=30 \mathrm{~s} ; 3-\tau_{\mathrm{rev}}=60 \mathrm{~s}$
Ires $=2,5 \mathrm{~A} ; \mathrm{Cpp}_{\mathrm{min}}=813 \mathrm{mg} / \mathrm{dm}^{3} ; \mathrm{tk}_{\mathrm{k}}=10 \mathrm{~min} ; \mathrm{Ifor}=1,5 \mathrm{~A}$

Fig. 2. Dependences of the residual concentration of petroleum products on variable parameters. 

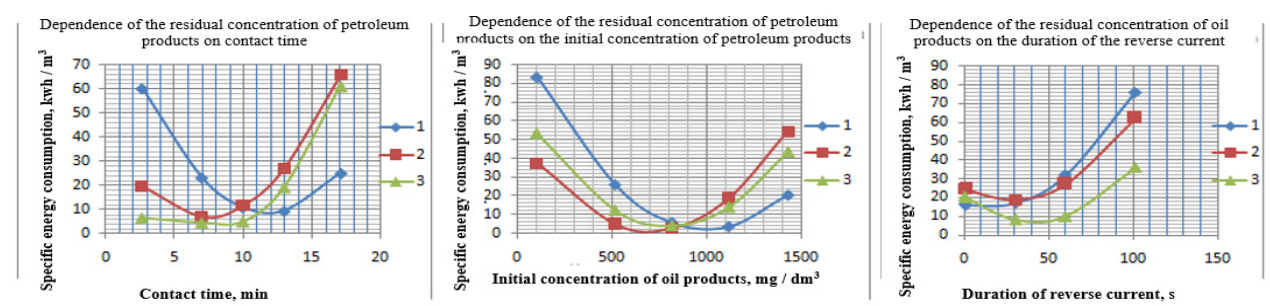

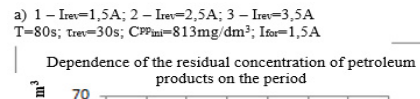

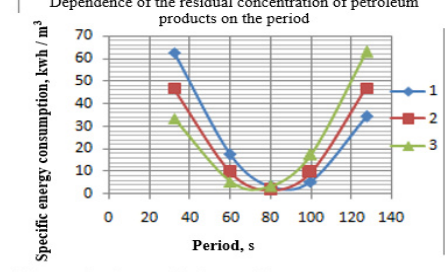

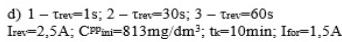

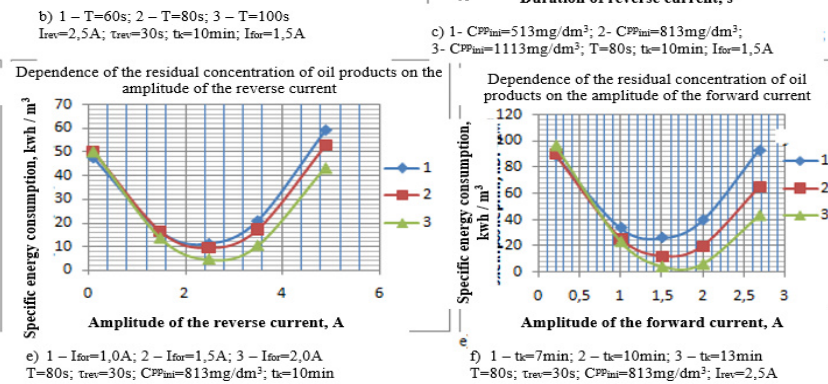

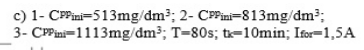

Dependence of the residual concentration of oil
products on the amplitude of the forward current

Fig. 3. Dependences of specific energy consumption on variable parameters.

Anodic dissolution of aluminum occurs during the process of wastewater electrocoagulation, containing emulsified oil products. In a slightly acidic and neutral medium, sparingly soluble aluminum hydroxide $\left[\mathrm{Al}(\mathrm{OH})_{3}\left(\mathrm{H}_{2} \mathrm{O}\right)_{3}\right]$ is formed with a highly developed surface, which determines the high adsorption capacity with respect to particles of oil products and suspended solids [5]. In order to determine the composition of the sediments generated during the process of wastewater electric treatment, containing emulsified oil products, a differential thermal analysis was performed with the use of NETZSCH STA $449 \mathrm{~F} 1$ instrument in the range of 30/20.0 (k/ min) / 1000 in the DSC TG mode (Figure 4, where DSC - differential scanning calorimetry, $\mu \mathrm{V} / \mathrm{mg}$; $\mathrm{TG}$ - mass change curve, $\%$; DTC - differential thermogravimetric curve, $\% / \mathrm{min}$ ). The thermogram of sediment is shown in Figure 4. [5]

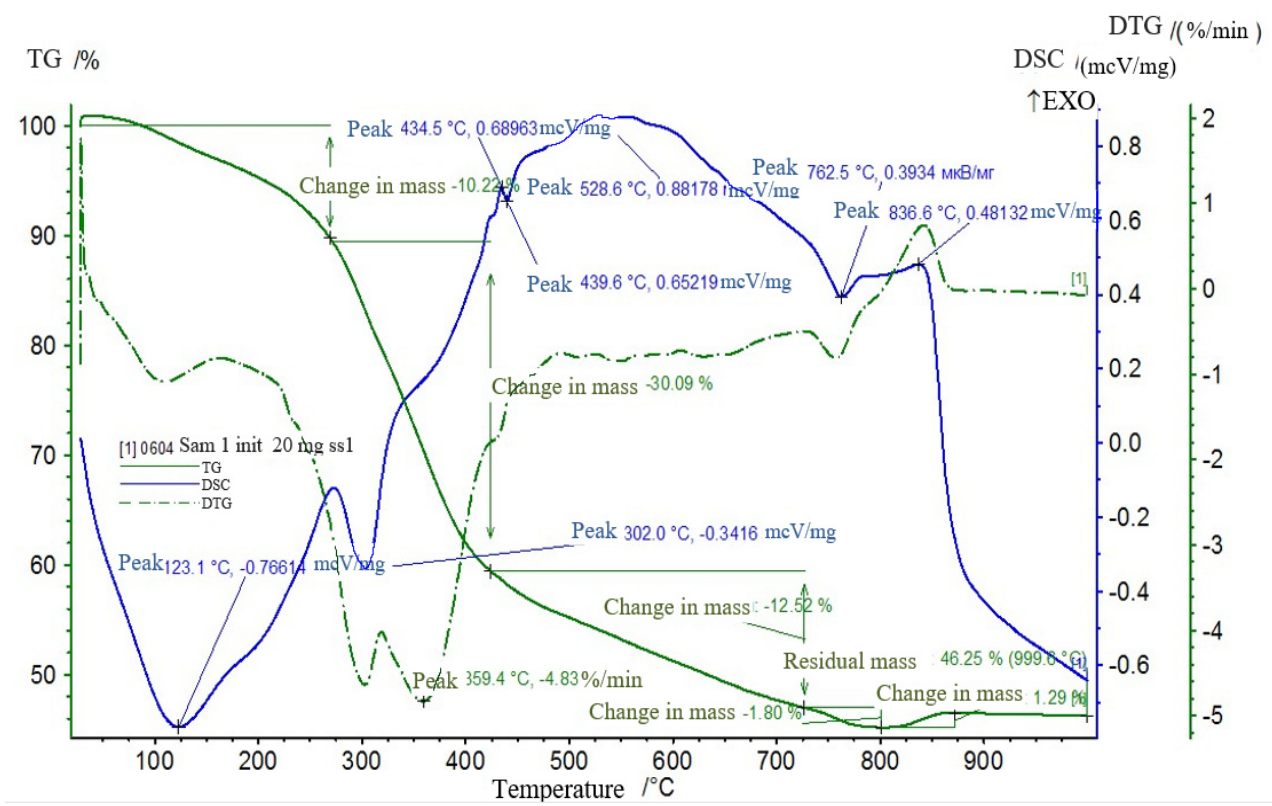

Fig. 4. Thermogram of oil-containing wastewater sludge. 
In order to study the structure and composition of the sludge, X-ray phase analysis method was also used on D8-ADVANCE diffractometer of German company Bruker-ASX, and a diffractogram of the sewage sludge containing emulsified oil products was obtained, which is shown in Figure 5. Thermal effects: $\mathrm{t}=123.1{ }^{\circ} \mathrm{C}$ are characteristic for dehydration; at $\mathrm{t}=302.0{ }^{\circ} \mathrm{C}$, the peak is explained by the polymorphic transformations of aluminum hydroxides; at $\mathrm{t}=439.6{ }^{\circ} \mathrm{C}$ and $\mathrm{t}=528.6{ }^{\circ} \mathrm{C}$, thermal effects are characteristic for the combustion of oils; at $\mathrm{t}=762.0{ }^{0} \mathrm{C}$, carbonates decompose [6]. The sediment diffraction pattern (Figure 5) shows the degree of sediment ordering is low; the substance is mainly presented in an amorphous form. Diffraction maxima at $d=4.81 ; 4.69 ; 4.34 ; 3.025 ; 2.45$ and $2.27 \mathrm{~A}$ indicate the presence in the precipitate of a phase in the form of $\mathrm{Al}_{2} \mathrm{O}_{3} \cdot 3 \mathrm{H}_{2} \mathrm{O}$, at $\mathrm{d}=3.83 ; 2.48 ; 1.9 ; 1.6$ the presence of carbonates is observed. X-ray phase analysis confirms the data of thermogravimetric analysis.

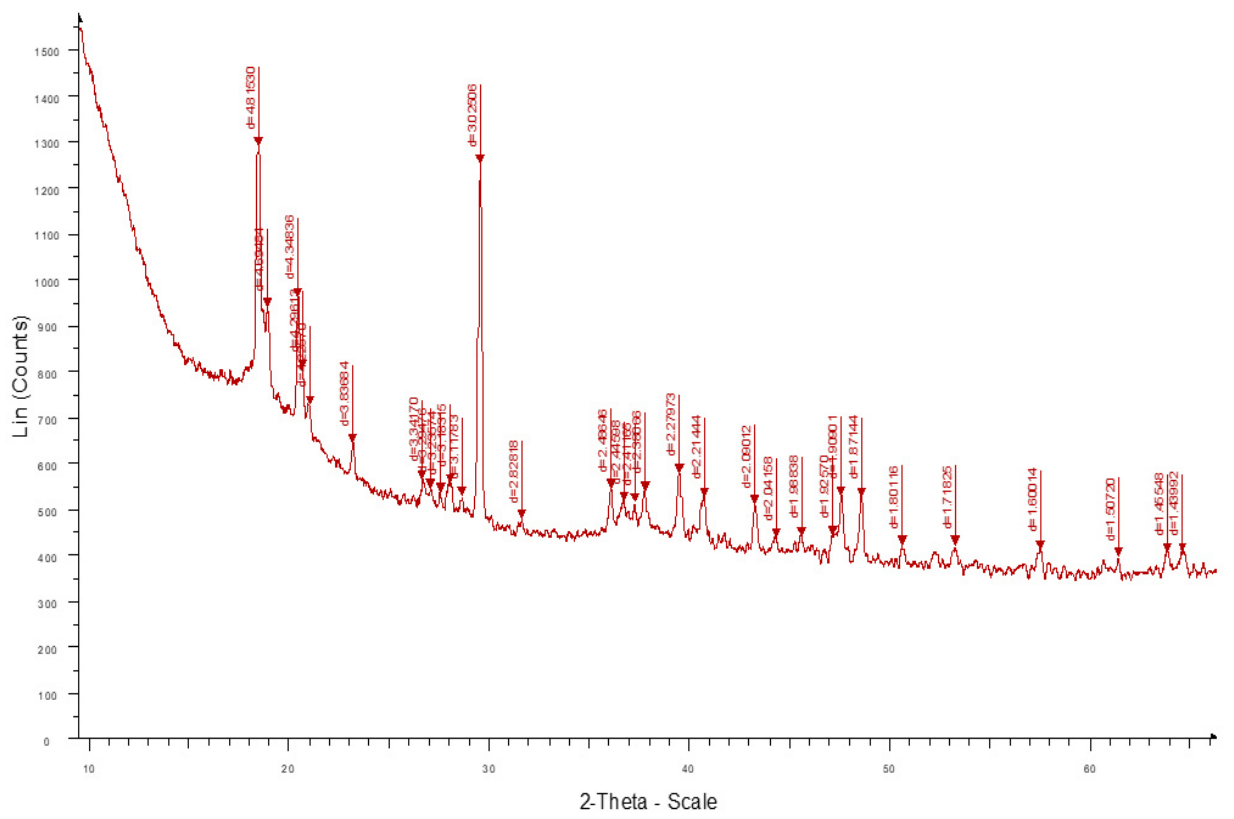

Fig. 5. Diffraction pattern of oil emulsion wastewater sludge.

No doubt, that sewage sludge can be disposed of as additives in the production of building materials $[4,7]$. The studies were conducted jointly with the Department of Building Materials and Technology of Building Production " to find the possibility of utilizing sludge in the production of arbolite mixtures and gypsum products considering the sludge composition, in order to develop low-waste technological processes that can reduce the industrial impact on the environment.

The composition for arbolite: Portland cement - 300-500 kg/m 3 ; wood crushed - 150 $200 \mathrm{~kg} / \mathrm{m} 3$; water $-220-250 \mathrm{l} / \mathrm{m}^{3}$; sediment $-3-3.5 \mathrm{~kg} / \mathrm{m}^{3}$ was prepared for study. It was established that additive introduction for sludge from oily wastewater, in an amount from 2.0 to $2.5 \%$, provided a significant decrease in the average density (mass volume), while the porosity of the product was increasing and, therefore, its heat-insulating properties were improving. 


\section{Discussion}

The processes of anodic dissolution of metals form the electrocoagulation method's basis, used for wastewater treatment. Electrocoagulation is accompanied by electricity and metal consumption. The current shape influences the energy consumption in the process of obtaining metal ions, generated in the electrolyte [5, 8]. Direct and alternating electric currents are used for the electrochemical coagulation of colloid-dispersed particles [1, 2,9]. It was established [6] that, an insufficient degree of particles coagulation is observed due to sorption on the anode of negatively charged oil particles that impede the generation of $\mathrm{Al}^{3+}$ ions in the process of wastewater treatment with the use of direct current.

The contact resistance of anode-solution increases within energy consumption in addition to slowing down the anode process.

There is a decrease in metal current output compared to direct current, because the overvoltage does not have time to instantly take the current density value under stationary conditions with rapid changes in its density (50 times per second), during the process of wastewater treating with alternating current [1]. In addition, a certain amount of electricity is spent on recharging the capacity of the double electric layer. Electrocoagulation of wastewater can be carried out by reverse current with the same duration and amplitude of a positive and negative pulse, which frequency is determined by the set time of the plates' polarity reversal.

The use of reverse current makes it possible to reduce the energy consumption, however, the cleaning effect decreases with an increase in the duration of electrodes continuous operation, as it is shown in a scientific paper [5]. A method for treating oilcontaining effluents with an asymmetric current was developed in order to stabilize the process [8]. Asymmetric current can be obtained using the device [3], developed at School of Engineering and Construction of SibFU, which is shown in Figure 1.

The switch was made in the form of a key current inverter on semiconductor devices (thyristors or transistors), connected to the outputs of the control unit in the setup scheme for obtaining asymmetric current, unlike the known device. The proposed device is equipped with a computer, its inputs are connected to the sensors of controlled parameters, and the outputs are connected to the inputs of the control unit and, so it is possible to choose the optimal current shape by changing the duration of the reverse current and the pulse amplitude in the processing of oil-containing wastewater with different concentrations of oil products with an asymmetric current.

The reverse current energy (negative pulse), which is used to activate the anode over its entire surface and to destroy the oil film by the released hydrogen, can be minimal, in this case the specific energy consumption will be minimized. The amplitude of negative polarity pulse should be greater than its amplitude of positive one, in this case, the pulse duration can be less than the pulse of positive polarity and selected depending on the oil products concentration in wastewater with a high cleaning effect.

\section{Conclusions}

1. The possibility of carrying out effective treatment in a stable mode has been established as an experimental studies' result of the electrocoagulation process of oily wastewater with an asymmetric current.

2. A study of composition and structure of oil-containing sediment to develop technology for its disposal as an additive in the production of arbolite mixtures and gypsum products was made. 


\section{References}

1. E.Yu. Nikiforova, A.B. Kilimnik. Bull. TSTU, 15, 604-614 (2009)

2. D.G. Gospodinov, A.V. Shkarin. Patent RF 2307797 October 10 (2007)

3. D.G. Gospodinov, A.V. Shkarin. Patent RF 2307797 October 10 (2007)

4. T.I. Khalturina, O.V. Churbakova, A.S. Shakora, Vestnik (2000)

5. T.I. Khalturina, T.M. Rudenko, O. Churbakova, Insti. Ci. Eng., 8, 56-60 (2008)

6. V.P. Ivanova et al, Nedra (2002)

7. L.M. Sokolov, A.N. Petrov, Wat. Sup.San. Equi., 8,15 - 17(2000)

8. T.I. Khalturina, T.I. Pazenko, G.M. Zograf, L.V. Stafeychuk, Certificate, USSR 981240 December 15 (2001)

9. T.I. Khalturina, S.A. Kozlova, O.V. Churbakova, Bull., 5, 51-58 (2017)

10. L.M. Sokolov, A.N. Petrov, Wat. Sup.San. Equi., 8,15 - 17(2000) 